\title{
Incidental Vocabulary Learning And Recall By Intermediate Foreign Language Students: The Influence Of Marginal Glosses, Dictionary Use, And Summary Writing \\ Zargham Ghabanchi, Ferdowsi University of Mashhad, Iran Elham Sadat Ayoubi, Sabzevar Tarbiat Moallem University, Iran
}

\begin{abstract}
This study is an attempt to compare the effect of four reading conditions on incidental vocabulary learning and recall of intermediate EFL learners. A sample population of 120 Iranian intermediate students read two short passages in one of four reading conditions: 1) L1 Marginal Glosses (MG1 - provision of L1 translations of unknown words), 2) L2 Marginal Glosses (MG2 provision of L2 meanings of unknown words), 3) Dictionary Use (DU - opportunity to use a dictionary), or 4) Summary Writing ( $S W$ - writing a little summary of both texts using new words). After reading, students were tested for their recall of 30 words that had appeared once to six times in the texts. Two weeks later, they were tested again to check long-term retention of words. Support was found for the hypothesis that the four vocabulary learning conditions and the time interval between the two tests have a meaningful influence on the retention of the meaning of unfamiliar target words. The other hypothesis assumed that the retention of the meaning of the words is the highest in SW group, and it lowers in DU group, MGlgroup and MG2 group respectively. All of the four reading conditions had a significant effect on incidental learning and recall of the words, but neither the immediate nor the delayed tests revealed significant differences among the four types.
\end{abstract}

Keywords: Incidental Vocabulary Learning; Short-Term/Long-Term Retention; L1/L2 Marginal Gloss; Dictionary Use; Summary Writing

\section{INTRODUCTION}

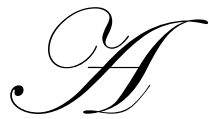

ttention to vocabulary plays a vital role in the profession of language teaching. This vital role necessitates reliable and efficient programming for this language component. Although some teachers may think that vocabulary learning is easy, learning new words has always been challenging for learners. Usually the students utilize different ways of learning words, such as using flash cards, notebook, referring to bilingual and monolingual dictionaries to check the meaning, or giving some synonyms and antonyms, to name but a few. In spite of these efforts and difficulties, vocabulary is still a challenging issue. This raises a fundamental query of which method could be used to make vocabulary less of a struggle. One possible answer to the problem is applying teaching vocabulary learning strategies.

Research into language learning strategies began in the 1960s and since the mid 1980s, vocabulary learning has been drawing growing attention from ESL researchers, particularly, the 1990s, witnessed a noticeable number of publications, vocabulary is now a current focus in ESL pedagogy and research (Wei, 2007). Incidental vocabulary learning, specifically, has proven to be a controversial issue and a question of long debate with regard to its impacts on the process of vocabulary learning (Coady, 1997; Zhang, 2001; De Ridder, 2002; Karp, 2002; Takeuchi, 2004; Pulido, 2007; Prichard, 2008). 
It is apparent that lexical items can be acquired incidentally through reading (Hulstijn, 2001; Rieder, 2003; Schmitt, 2008). However, incidental vocabulary learning through reading is not always effective, especially for ESL/EFL learners (Laufer, 2001). Frequently, L2 vocabulary gains from reading are relatively small and not necessarily efficient (Hulstijn, 1992; Day and Bamford, 1998; Min, 2008). Such small gains of words learned solely by reading could be attributed to several factors - the major one being the lack of noticing. Schmidt (1995) emphasizes that conscious attention is necessary for learning to take place, and noticing is generally the first stage of learning. However, it is highly possible that while reading, learners usually fail to notice unfamiliar words, especially when they can understand the global message of the text without knowing those words.

\section{RESEARCH QUESTIONS AND HYPOTHESES}

Two major research questions are addressed:

1. Do the four vocabulary learning conditions and the time interval between the two tests have meaningful influence on the retention of the meaning of unfamiliar target words?

2. Is there any difference between learners' vocabulary learning and long-term retention in the four conditions of reading?

To answer the above questions, the following hypotheses are formulated:

1. The four vocabulary learning conditions and the time interval between the two tests do not have a meaningful influence on retention of the meaning of unfamiliar target words.

2. There is no significant difference between learners' vocabulary learning and long-term retention in the four conditions of reading.

In this research, it is hypothesized that in the SW group, retention of the words is significantly higher than the other three groups in both tests. Moreover, the retention of the meaning of the words is the highest in the SW group, and it lowers in the DU, MG1, and MG2 groups, respectively. These assumptions are grounded on the following reasoning: On the basis of the questionnaire, students were expected to be unfamiliar with the target words. Furthermore, it was anticipated that the SW group would perform better because of what Hulstijn (1992) calls "deeper" processing (greater mental effort) during initial word learning which leads to an increase in retention. Joe (1995) found that tasks encouraging such deeper word processing, including retrieval of stories that had been read and generative use of the new words in retelling, led to better retention.

\section{REVIEW OF RELATED LITERATURE}

Convictions are strong among many language professionals that contextualized that vocabulary learning is more effective than learning words in a list. Oxford and Scarcella (1994), for example, observe that while decontextualized learning (word lists) may help students memorize vocabulary for tests, students are likely to rapidly forget words from lists.

McCarthy (1990) argues that a word learned in a meaningful context is best assimilated and remembered. Moreover, in recent literature dealing with vocabulary acquisition, there can be seen increasing advocacy for explicitly teaching words out of context at an early stage of language acquisition with more context-based vocabulary learning taking place at later stages of language development (e.g. Coady, 1997b; Meara, 1997). Researchers in both L1 and L2 acquisition have studied the role of reading in the acquisition of vocabulary knowledge. In vocabulary acquisition through reading, word knowledge appears to be elaborated gradually through multiple exposures to words in varied discourse contexts (Nagy \& Herman, 1987). Many words are picked up during these exposures while the reader's goal is to comprehend the meaning of the language read, rather than to learn new words. This "picking up" is usually referred to as incidental learning. Laufer and Hulstijn (2001) define incidental learning as a by-product of another activity, such as reading or communication, without the learner's conscious decision, or intention, to learn the words. 
On first sight, it seems that vocabulary growth stems partly from reading; however, for some reason, readers often fail to spontaneously learn the meanings of previously unknown words encountered in texts. Sometimes, learners simply fail to notice the presence of unfamiliar words and at other times, they do notice their presence but decide to ignore them (Hulstijn, Hollander, \& Greidanus, 1996). Furthermore, gaining the words is dependent on reader's L2 proficiency adequate to use the cues, and the formal similarity of the new words to known words in the L1 (Haynes, 1993). As the meanings of unknown words are not often inferable from the context and readers make erroneous inferences (Hulstijn, 1992), there is a need to a gloss. Factors that positively affect incidental vocabulary learning are: (a \& b) the provision of marginal L1 and L2 glosses, (c) the use of a dictionary and (d) the practice of new words in writing a summary of the text.

\section{L1 vs. L2 Glosses}

Researchers have examined the effectiveness of glosses on incidental vocabulary learning (Hulstijn, 1992, 1993; Hulstijn, Hollander, \& Greidanus, 1996; Jacobs, Dufon, \& Hong, 1994; Paribakht \& Wesche, 1997). Comparison of gloss conditions with non-gloss conditions has revealed the advantage of having glosses for enhancing incidental vocabulary learning. The question, therefore, has shifted to which gloss type is most effective. Attempts to compare the effectiveness of L1 and L2 glosses have brought mixed results, some indicating no difference between the two types and others suggesting the advantage of one gloss type over the other (Chen, 2002; Jacobs et al., 1994; Miyasako, 2002).

To understand the effectiveness of L1 and L2 glosses better, it is important to examine how words and concepts are represented in L2 learners' minds. Kroll \& Stewart (1994) presented their model to include both the lexical links of the word association model and the conceptual links of the concept mediation model, and delineated the developmental shift through differentiation of the strength of the conceptual links. Figure 1 shows this model which suggests that L1 conceptual links are stronger than L2 conceptual links because L2 words are associated with their L1 translations for accessing meaning in early stages of L2 acquisition; and a direct link to concepts from L2 words can be possible only with increasing proficiency (Kroll \& Sunderman, 2003, p.114). The current research uses this model as a theoretical base to formulate a part of the hypothesis, and through this model, one could expect that the L1 glosses would be more effective than L2 glosses for vocabulary learning since the word-to-concept connections are stronger for L1 than for L2 for the participants in this study who are regarded as intermediate learners.

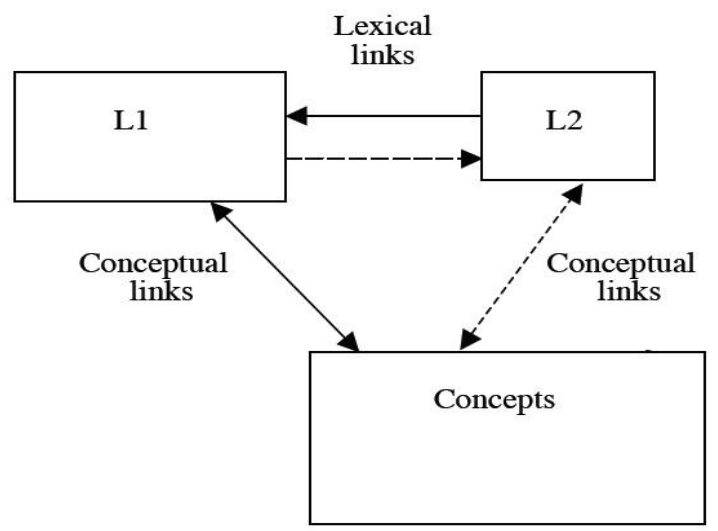

Figure 1: Hierarchical Model in Mind (Adapted from Kroll \& Stewart, 1994)

\section{Dictionary Use}

Noticing language is the first step to acquisition (Schmidt, 2001), and looking a word up in the dictionary and identifying the correct definition calls more attention to the word, which increases the chance that the word will be retained (Peters, 2007; Pulido, 2007; Robinson, 2003). However, looking up nearly all unknown words without careful attention would be unlikely to lead to retention. In studies by De Ridder (2002) and Roby (1999) on the learners' overuse of electronic glosses, it is hypothesized that looking up too many words without careful consideration led to shallow processing and short-term retention. 
Looking up words may be quicker and easier when using online or electronic dictionaries, but it can become so effortless that it may decrease vocabulary retention. Therefore, in this study, to have this effort of looking up the words, the traditional paper dictionaries were used. Dictionaries should be used for learners when reading text above their level to reach the comprehension threshold (roughly 95\% coverage). According to Prichard (2008), learners reading texts near or at their level should very rarely use dictionaries, if at all.

However, it still needs to be considered which lexical items should be looked up and which words can be ignored (Hulstijin, 1993). When teaching academic reading, Grabe and Stoller (2004) suggest that instructors focus students' attention on words that are frequent and useful to acquire and those that are related to the main points of the reading passage.

\section{Summary Writing}

The acquisition of new L2 vocabulary knowledge is viewed as a multi-stage process that involves many factors. For example, factors such as their form or collocation with other words may influence the learner's attention to particular word features, contextual clues, or words stored in memory, as they take in and integrate novel lexical information into existing knowledge (Wesche \& Paribakht, 2000). Any new knowledge of a word that is retained is likely to be modified, strengthened, and elaborated while it is used to create new text. It is through this production and learner-initiated use of new knowledge that a lexical entry "matures" in the mental lexicon.

It is self-evident that second language acquisition (SLA) cannot take place if learners have no access to second language (L2) input. Krashen (1985) proposed that input has to be comprehensible, yet he ignored output and argued that speaking is the result of acquisition and not its cause. Contemporary cognitive psychologists, however, maintain that the transfer between comprehension and production cannot occur automatically; thus, adequate input is necessary, but neither sufficient nor an efficient condition for SLA (Skehan, 1998). Swain $(1985,1995)$ proposed the Comprehensible Output Hypothesis, which maintains that output has three major roles to play in SLA - noticing, hypothesis-testing, and metalinguistic talk. Swain particularly emphasized the role of 'pushed output'. Swain's "Output Hypothesis" (1985) argues that through producing language, either spoken or written, language learning may occur.

There are some other empirical evidences to prove that output production affects incidental vocabulary learning (Newton, 1995; R. Ellis, 1994; Ellis \& He, 1999; Joe, 1995; Hulstijn \& Trompetter, 1998).

\section{Long-term Retention of the Words}

One of the biggest problems with vocabulary learning, according to Waring (2002) and which all the second language learners have experienced, is that what we learn today will be forgotten tomorrow.

Language learners need all the information of the language to be learned transferred into long-term memory (LTM). It has therefore been of interest to the cognitivists how this 'encoding' process could be achieved, how LTM operates, and how information can be retrieved from this store, reversing the path and transferring information from LTM to STM (Hauptmann, 2004). To this end, learners need appropriate strategies to achieve success (Mayer, 1998). The main way of transferring from working memory (WM) to LTM is by finding some pre-existing information in the LTM to attach the new information to. In the case of vocabulary, it means finding some element already in the mental lexicon to relate to the new lexical information (Schmitt, 2000, p.132). The native keyword is such an element. People have often experienced not being able to remember a word that they are normally familiar with, even though they can remember many of its characteristics, e.g. meaning, gender, number of syllables, etc. (Brown \& McNeil, 1966). It is only when they put all this information together that there will be complete retrieval - eventually.

\section{METHOD}

Vocabulary is not learned once it has been one or two times. The learner needs to learn the word's multiple uses, the words it goes with, and much more. Research also suggests that it takes between 8 and 20 meetings of a word before it can be said that one has 'learned' it, which means that the learner can understand it when it is met in 
reading and listening, but not necessarily use it in speaking and writing. To use the word productively, a lot more knowledge of the word is needed. There is a big difference between learning a word only at the meaning-sound level and being able to use it. Thus, the learner needs to work extra hard to use the word productively. Initially, the learners only need a basic picture of the word, such as a rough meaning or a translation, and it will be enough (Waring, 2002).

\section{The Design of the Study}

Intermediate learners of English as an L2 read two short texts under one of four conditions: 1) L1 Marginal Glosses (MG1 - provision of L1 translations of unknown words), 2) L2 Marginal Glosses (MG2 - provision of L2 meanings of unknown words), 3) Dictionary Use (DU - opportunity to use a dictionary), or 4) Summary Writing ( $\mathrm{SW}$ - writing a little summary of both texts using new words).

Students were supposed to read the texts in each of four above-mentioned conditions and answer the test which contained a list of 30 words (two groups of 15 words, each occurring one to six times in the text). Students were tested for their receptive knowledge of these 30 target words. They were also tested two weeks later for their long-term retention.

\section{Participants}

Students participating in this experiment were 120 female Persian speakers of English as a foreign language at the senior level in three different high schools in Iran. To ascertain that the four groups' English proficiency was at the same level prior to different instructional treatments, the researcher performed an independent samples t-test to compare participants' final exam scores from the previous semester. Then a questionnaire, accompanying the list of vocabulary words, was given to students before participating in the research to make sure that the words were completely new for them. This was employed to assess students' knowledge of 30 vocabulary words. No significant difference existed between these four groups' English proficiency levels.

\section{Reading Materials}

Two roughly-equivalent non-fictional texts were used, both being quite similar in terms of readability, lexical profiles, and genre. The short texts that students read were "Thirteen Equals One" and "The Double Life of Alfred Bloggs" from Developing Skills by L. G. Alexander. They contained 519 words. Thirty of them, estimated to be unfamiliar to most senior high school students, were selected as target words. These estimations were based on extensive piloting and giving questionnaires to students. The texts were slightly adapted as follows: 1) The average readability of their English textbooks in high school and the books covered in their language institutions was estimated and 2) these two texts were then chosen in accordance to their readability to match the learners' relative proficiency. The text difficulty was estimated through Fog index of readability. With this approach, the following formula is used:

Text difficulty $=\frac{\text { number of words }}{\text { number of sentences }}+\left(\frac{\text { number of } 3 \text { syllable words }}{\text { number of words }}\right) 40$

\section{Procedure}

Twelve reading plus testing sessions were held to test the learners' short-term acquisition of the 30 new targeted words. In each session, ten different students participated and every four classes were held in one language institute. Students were randomly assigned to the MG1, MG2, DU, and SW conditions; therefore, each group of ten students was in a separate classroom. Students were not told in advance that they would later be tested on their knowledge of the meanings of words in the texts; instead, they were told that they would have to answer comprehension questions after reading. This was done to create conditions for incidental vocabulary learning: Students' attention was turned away from the particular unknown words and directed toward an understanding of the texts. Thus, instead of having to answer comprehension questions for which they had prepared, students were tested on their knowledge of vocabulary. The administration of the posttest took 15 minutes in which they were asked to write the meaning of targeted words as much as they can remember. 
One point remained and it was the time allocated to the learners' reading session, and it was the time duration of reading the texts. It was obvious that the students in the SW group needed more time to write their summaries than the other three groups. Also, those in the DU group needed more time than the MG1 and MG2 conditions because they had to check the meaning of the new words in their dictionaries. Pilot testing showed that the time needed for the SW condition to read the texts and write their summaries was 20 minutes; for the DU condition to read and check their dictionaries, it was 15 minutes; for the MG2 group, ten minutes, and the MG1 condition, eight minutes. As the reading was supposed to be accomplished in 20 minutes for all four groups, the SW condition had the gloss at hand from the beginning of the session, the DU group had their dictionaries after five minutes of reading, the MG2 condition benefited their marginal L2 gloss after ten minutes, and the MG1 group received their $\mathrm{L} 1$ gloss 12 minutes after the reading began (Table 1).

Table 1: Time of the Reading Session and the Test

\begin{tabular}{|l|c|c|c|c|}
\hline \multicolumn{1}{|c|}{ Time Condition } & $\begin{array}{c}\text { Total Time of } \\
\text { Reading Session }\end{array}$ & $\begin{array}{c}\text { Time of Reading } \\
\text { WITHOUT Gloss }\end{array}$ & $\begin{array}{c}\text { Time of Reading } \\
\text { WITH Gloss }\end{array}$ & Time of the Test \\
\hline SW & $20 \mathrm{~min}$ & 0 & 20 & 15 \\
\hline DU & $20 \mathrm{~min}$ & 5 & 15 & 15 \\
\hline MG2 & $20 \mathrm{~min}$ & 10 & 10 & 15 \\
\hline MG1 & $20 \mathrm{~min}$ & 12 & 8 & 15 \\
\hline
\end{tabular}

Two weeks later, the same post-test was administered again, without announcement to students in advance, to check their long-term vocabulary retention. This took about 15 minutes.

The responses of both post-tests (Tests 1 and 2) were checked by the researcher, independently of each other. If the meaning of the targeted word was written correctly, either in Persian or English, it was credited with a whole point and a zero if completely incorrect or if no response was given. Each test was graded out of 30 .

\section{DATA ANALYSIS AND RESULTS}

The first hypothesis was "The four vocabulary learning conditions and the time interval between the two tests do not have a meaningful influence on the retention of the meaning of unfamiliar target words". To conduct the analysis required to verify this hypothesis, a univariate analysis of variance (ANOVA) was run. The ANOVA was performed for the scores with a significance level set at .05 (Table 2).

Table 2: Univariate Analysis of Variance Tests of Between-Subjects Effects

Dependent Variable: Scores

\begin{tabular}{|c|c|c|c|c|c|c|}
\hline \multicolumn{2}{|l|}{ Source } & Type I Sum of Squares & df & Mean Square & $\mathbf{F}$ & Sig. \\
\hline \multirow[t]{2}{*}{ Intercept } & Hypothesis & 84938.438 & 1 & 84938.438 & 1546.335 & .000 \\
\hline & Error & 6371.750 & 116 & $54.929^{\mathrm{a}}$ & & \\
\hline \multirow[t]{2}{*}{ Test } & Hypothesis & 592.204 & 1 & 592.204 & 62.567 & .000 \\
\hline & Error & 1097.950 & 116 & $9.465^{\mathrm{b}}$ & & \\
\hline \multirow[t]{2}{*}{ Learning } & Hypothesis & 1246.312 & 3 & 415.437 & 7.563 & .000 \\
\hline & Error & 6371.750 & 116 & $54.929^{\mathrm{a}}$ & & \\
\hline \multirow[t]{2}{*}{ Number } & Hypothesis & 6371.750 & 116 & 54.929 & 5.803 & .000 \\
\hline & Error & 1097.950 & 116 & $9.465^{\mathrm{b}}$ & & \\
\hline \multirow[t]{2}{*}{ Test * Learning } & Hypothesis & 312.346 & 3 & 104.115 & 11.000 & .000 \\
\hline & Error & 1097.950 & 116 & $9.465^{\mathrm{b}}$ & & \\
\hline \multirow[t]{2}{*}{ Test $*$ Number } & Hypothesis & 1097.950 & 116 & 9.465 & . & . \\
\hline & Error & .000 & 0 &.$^{\mathrm{c}}$ & & \\
\hline
\end{tabular}
a. MS(number)
b. MS(test * number)
c. $\mathrm{MS}$ (Error) 
There are four hypotheses to be examined in order to examine this hypothesis:

1. $\quad \mathbf{H}_{\mathbf{0}}$ : The effect of learning condition equals zero; in other words, learning condition has no significant effect on the learners' scores. As Table 2 depicts, the repeated measure ANOVA shows that the null hypothesis is rejected $(\mathrm{F}=7.563, .000<<.05)$.

2. $\mathbf{H}_{0}$ : The effect of test equals zero; in other words, learning condition has no significant effect on the learners' scores. Table 2 shows that the null hypothesis stated here is rejected $(\mathrm{F}=62.576, .000<<.05)$. According to repeated measure ANOVA, learning condition has a significant effect on the learners' scores.

3. $\quad \mathbf{H}_{0}$ : The interaction effect of learning condition and test equals zero. According to Table 2, the null hypothesis is rejected and the repeated measure ANOVA manifested a significant interaction affect between tests and learning conditions $(\mathrm{F}=11, .000<<.05)$.

4. $\quad \mathbf{H}_{\mathbf{0}}$ : The effect of participants equals zero; in other words, participants have no significant effect on their scores. Table 2 reveals that the repeated measures ANOVA failed to prove the null hypothesis. Consequently, participants have a significant effect on the scores.

Table 3: Case Summaries (Mean)

\begin{tabular}{|l|c|c|}
\hline \multirow{4}{*}{$\begin{array}{l}\text { S.T.M } \\
\text { (TEST 1) }\end{array}$} & Learning Procedure & Scores \\
\cline { 2 - 3 } & MG1 & 21.83 \\
\cline { 2 - 3 } & SW & 21.93 \\
\cline { 2 - 3 } & DU & 20.07 \\
\cline { 2 - 3 } & MG2 & 17.70 \\
\hline \multirow{4}{*}{$\begin{array}{l}\text { L.T.M } \\
\text { (TEST 2) }\end{array}$} & Total & 20.38 \\
\cline { 2 - 3 } & MG1 & 16.10 \\
\cline { 2 - 3 } & SW & 22.47 \\
\cline { 2 - 3 } & DU & 16.47 \\
\cline { 2 - 3 } & MG2 & 13.93 \\
\hline \multirow{4}{*}{ Total } & Total & 17.24 \\
\cline { 2 - 3 } & MG1 & 18.97 \\
\cline { 2 - 3 } & SW & 22.20 \\
\cline { 2 - 3 } & DU & 18.27 \\
\cline { 2 - 3 } & MG2 & 15.82 \\
\cline { 2 - 3 } & Total & 18.81 \\
\hline
\end{tabular}

To sum up, the effect of Test and Learning Procedure is significant. Both of these factors are effective in the scores of the learners. Also, the interactive effect of these two is significant.

Therefore, the first null hypothesis was rejected. It means that the four vocabulary learning conditions and the time interval between the two tests HAVE a meaningful influence on the retention of the meaning of unfamiliar target words.

The second hypothesis was "There is no significant difference between learners' vocabulary learning and long-term retention in four conditions of reading." In order to compare the four conditions, first the average scores of the participants in both Test 1 and Test 2 are employed from the Mean Case Summaries (Table 3) and the graphs are drawn (Graph 1). 


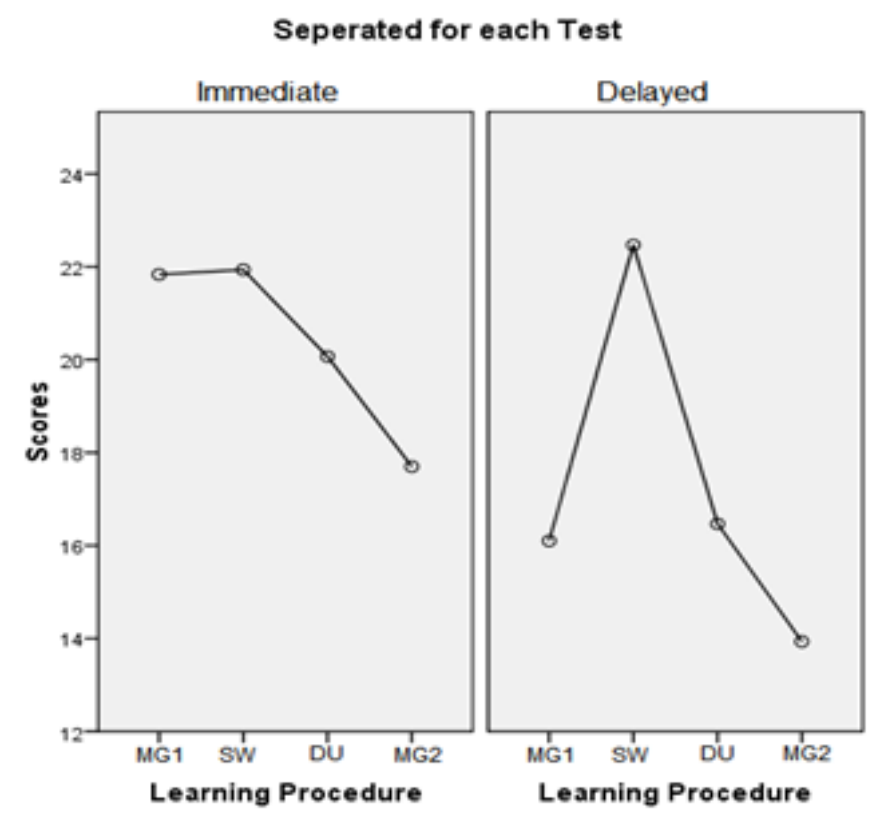

Graph 1: Score Mean Plots, Separated for Immediate and Delayed Tests

From the above graphs and Table 3, it is concluded that the average score of the participants in the SW group is higher than the other groups. In addition, it is inferred that the SW condition had a better result in long-term retention of the targeted words (Test 2), whereas the other conditions of MG1, MG2 and DU showed higher scores in the vocabulary test immediately after the reading session (Test 1). There remains one important question: "according to the statistical rules, is this difference significant?"

By the use of Duncan's multiple range test (MRT), the average scores of the participants in the MG1, MG2, DU and SW conditions can be compared to check the significance of the difference.

$S_{\bar{y}}=\sqrt{9.465}=3.0765$

For four conditions $(\mathrm{p}=4)$, the average scores with 116 degree of freedom $(\mathrm{df}=116)$ for the error, according to the analysis of variance table, MS (error) equals 9.465 for the Test and the interactive effect of learning* Test, that is the amount of MS (Test* number) with 116 degree of freedom.

The 5\% higher spots of the Duncan's meaningful ranges $\mathrm{r}_{.05}(\mathrm{p} . \mathrm{f})$ are calculated and illustrated in Table 4:

Table 4: The 5\% Higher Spots of the Duncan's Meaningful Ranges

\begin{tabular}{|l|c|c|c|c|}
\hline Involved Ranges & $\mathbf{p}$ & $\mathbf{2}$ & $\mathbf{3}$ & $\mathbf{4}$ \\
\hline Duncan's Ranges & $\mathrm{r}_{.05}(\mathrm{p}, 116)$ & 2.77 & 2.92 & 3.02 \\
\hline The Lowest Meaningful Ranges & $\mathrm{S} \bar{y} \mathrm{r}_{.05}(\mathrm{p}, 116)$ & 8.52 & 8.98 & 9.29 \\
\hline
\end{tabular}

The ascendant sequence of average scores is shown in Table 5. 
Table 5: Ascendant Sequence of Average Scores

\begin{tabular}{|l|r|r|r|r|}
\hline STM $($ TEST 1$)$ & 17.70 & 20.07 & 21.83 & 21.93 \\
\hline LTM $($ TEST 2) & 13.93 & 16.10 & 16.47 & 22.47 \\
\hline $21.93-17.70=4.23 \ngtr 9.29$ \\
$21.83-17.70=4.13 \ngtr 8.98$ \\
$20.07-17.70=2.37 \ngtr 8.52$
\end{tabular}

Duncan's multiple range test (MRT) showed that summary writing strategy users made no more gains, both on the immediate and the delayed recall tests. This rejects the superiority of the SW condition over the other three conditions.

\section{DISCUSSION}

The first research question investigated the effect of L1 marginal glosses on vocabulary learning and retention across the time and a univariate analysis of variance revealed that L1 glosses have a significant effect on enhancing vocabulary learning and the retention of the meaning in the long term. Similarly, the second, third and fourth questions inquired into the effect of L2 gloss, dictionary use, and summary writing, the repeated measures ANOVA showed that they have significant effect on learning and recall of the words. The next research questions compared the four reading conditions and their influence on incidental vocabulary learning in both immediate and recall tests. After using Duncan's multiple range test (MRT), neither the immediate nor the delayed Test 1 and Test 2 revealed significant differences among the four types.

One part of the result is that the effectiveness of glosses, either in L1 or L2, did not differ in terms of enhancing vocabulary learning. This result corresponded with those of previous studies (Chen, 2002; Jacobs et al., 1994; Yoshii, 2006) showing no significant differences between L1 and L2 glosses. Furthermore, the current study confirmed the usefulness of glosses, regardless of language types, on incidental vocabulary learning (Jacobs et al., 1994; Hulstijn, 1992, 1993; Hulstijn et al., 1996: Knight, 1994; Paribakht \& Wesche, 1997). One possible reason why L1 was not found to be more effective than L2 glosses might be related to the nature of incidental learning. Learners pick up the meanings incidentally as they encounter words; however, the rate of learning is still low (Nation, 2001). Even for the L1 group, it was still difficult to make conceptual links in such a short period of time on the first exposure. It was assumed that the participants were low-intermediate or intermediate levels of learners who were still in early stages where the conceptual links between L1 and concepts would be stronger than the conceptual links between L2 and concepts, and a direct link to concepts from L2 words would not be possible (Kroll \& Sunderman, 2003; Yoshii, 2006). The participants might have had higher proficiency levels than expected or perhaps their levels varied, which may have contributed to the lack of differences between L1 and L2.

An interesting phenomenon emerged in the comparison of the four conditions. As seen in Graph 1, the SW group, in contrast to the other groups, performed a little better in Test 2 than in Test 1 . In fact, the statistical analysis showed no significant difference between the four groups; thus, the increase of scores in delayed test in the SW condition may be by chance or the participants might have reviewed the targeted words in the time interval of two weeks between the two tests. In other words, learning has taken place during the time between the two tests and Test 2 may not be considered a delayed one to check long-term retention. Further, the fact that the SW group sustained their scores over time in the delayed tests of this study leads to a suspicion that using the new words to write sentences more often and over a longer period of time might reveal an advantage of summary writing over the other strategies, but the length/term of this study does not allow any clear conclusion in this respect. An advantage of Summary Writing may appear only at a later time.

\section{CONCLUSIONS}

In their review of the question, Carter and McCarthy (1988) conclude that "it is difficult to draw precise lines to suggest when a move from keyword techniques, or translation in pairs, or from using a monolingual or bilingual dictionary, to context-based inferential strategies is best instituted" (p. 15). They suggest that there are "no clearly marked stages of transition" in the learning process and that, therefore, "a mixture of approaches should be adopted" (p. 15). One reason for this recommendation of a mixture of approaches is that all methods have advantages and disadvantages, which are discussed in the present paper. 


\section{Pedagogical Implications}

Teachers and material developers can foster vocabulary learning through reading in various ways:

1. Develop in learners an awareness of alternative vocabulary learning strategies that involve active processing of the target vocabulary.

2. Facilitate the burden of dictionary use because it interferes with the process of constructing a mental representation of text meaning. Provide marginal glosses when the text is read on paper or provide easy-toaccess electronic glosses when the text is read on computer.

3. Give learners a list of important words for subsequent intentional learning or encourage them to make sentences using the words.

4. Invite learners to regularly review these word lists. To that end, vocabulary exercises can be added to the printed text.

It is not recommended to replace incidental learning by intentional learning, but to follow up an incidental learning with intentional learning. Since intentional learning may require considerable effort, time, and, hence, motivation on the part of L2 learners, it is important that teachers and course designers provide materials that the learners consider relevant and interesting. According to Hulstijn, Hollander, and Greidanus (1996), "if a desire to know a word's meaning is the driving force, the mental elaboration required for acquisition will then come of its own accord." However, it is the teacher's and course designer's task to provide learners with easily accessible glosses and review opportunities.

\section{AUTHOR INFORMATION}

Zargham Ghabanchi received his BA in English language and literature from Mashed University, Iran. Then he received his MA in TEFL from Tehran Tarbiayyet Moderres University, Iran. He started his Ph.D. at the University of Liverpool, the UK in 1993 and Ph.D. was conferred to him in 1998 in Applied Linguistics. Now he has a chair at Fersdowsi University of Mashhad, and he has been the chancellor of Sabzevar Payam Noor University for five years. He has published several books and articles. E-mail: ghabanchi@um.ac.ir. Corresponding author.

Elham Sadat Ayoubi got her B.A. degree in English literature with the average score of 16.96 in 2008 from Sabzevar Tarbiat Moallem University. Being the top student, she was admitted to continue her education at the same university and got her M.A. in TEFL. She has been an English teacher since 2007 . E-mail: golden_waterfall1986@yahoo.com

\section{REFERENCES}

1. Brown, R., \& McNeil, D. (1966). The tip of the tongue phenomenon. Journal of Verbal Learning and Verbal Behavior, 5, 325-337.

2. $\quad$ Carter, R., \& McCarthy, M. (1988). Vocabulary and Language Teaching (p. 15). New York: Longman.

3. Chen, H. (2002). Investigating the effects of L1 and L2 glosses on foreign language reading comprehension and vocabulary retention. Paper presented at the annual meeting of the Computer-Assisted Language Instruction Consortium, Davis, CA.

4. Coady, J. (1997). L2 vocabulary acquisition through extensive reading. In J. Coady \& T. Huckin (Eds.), Second language vocabulary acquisition: A rationale for pedagogy (pp. 225-237). New York: Cambridge University Press.

5. Craik, F. and R. Lockhart (1972). Levels of processing: A framework for memory research. Journal of Verbal Learning and Verbal Behavior, 11, 671-684.

6. Day, R. and J. Bamford (1998). Extensive Reading in the Second Language Classroom. Cambridge, Cambridge University Press.

7. De Ridder, I. (2002). Visible or invisible links: Does the highlighting of hyperlinks affect incidental vocabulary learning, text comprehension, and the reading process? Language Learning \& Technology, 6 , 123-146.

8. Ellis, R. (1994). The Study of Second Language Acquisition. Oxford: Oxford University Press. 
9. Ellis, R., and He, X. (1999). The roles of modified input and output in the incidental acquisition of word meanings. Studies in Second Language Acquisition, 21, 285- 301.

10. Grabe, W., \& Stoller, F. (2004). Reading for academic purposes: Guidelines for the ESL/EFL teacher. In M. Celce-Murcia (Ed.), Teaching English as a second or foreign language (pp. 187-204). Boston, MA: Heinle \& Heinle.

11. Hauptmann, J. (2004). The effect of the integrated keyword method on vocabulary retention and motivation (PHD Thesis). University of Leicester.

12. Haynes, M. (1993). Patterns and perils of guessing in second language reading. In T. Huckin, M. Haynes, \& J. Coady (Eds.), Second language reading and vocabulary learning (pp. 46-64). Norwood: Ablex.

13. Hulstijn, J. H. (1992). Retention of inferred and given word meanings: Experiments in incidental vocabulary learning. In P. J. L. Arnaud \& H. Bejoint (Eds.), Vocabulary and applied linguistics (pp.113125). London: Macmillan.

14. Hulstijn, J. H. (1993). When do foreign-language readers look up the meaning of unfamiliar words? The influence of task and learner variables. The Modern Language Journal, 77, 139-147.

15. Hulstijn, J. H. (2001). Intentional and incidental second-language vocabulary learning: a reappraisal of elaboration, rehearsal and automaticity. Cognition and Second Language Instruction. P. Robinson. Cambridge, Cambridge University Press, pp. 349-381.

16. Hulstijn, J. H., Hollander, M., \& Greidanus, T. (1996). Incidental vocabulary learning by advanced foreign language students: the influence of marginal glosses, dictionary use, and reoccurrence of unknown words. The Modern Language Journal, 80(3), 327-339.

17. Hulstijn, J. H., \& Laufer, B. (2001). Some empirical evidence for the involvement load hypothesis in vocabulary acquisition. Language Learning, 51(3), 542-545.

18. Hulstijn, J. H. \& Trompetter, P. (1998). Incidental learning of second language vocabulary in computerassisted reading and writing tasks. Perspectives on Foreign and Second Language Pedagogy. Odense, Denmark: Odense University Press, pp. 191-200.

19. Jacobs, G. M., Dufon, P., \& Fong, C. H. (1994). L1 and L2 glosses in reading passages: Their effectiveness for increasing comprehension and vocabulary knowledge. Journal of Research in Reading, 17, 19-28.

20. Joe, A. (1995). Text-based tasks and incidental vocabulary learning. Second language research, 11, 149158.

21. Karp, A. S. (2002). Modification of glosses and its effect on incidental L2 vocabulary learning in Spanish. Unpublished doctoral dissertation, University of California, Davis.

22. Knight, S. (1994). Dictionary: The tool of last resort in foreign language reading? A new perspective. The Modern Language Journal, 78, 285-299.

23. Koyama, T., \& Takeuchi, O. (2004). How look up frequency affects EFL learning: An empirical study on the use of handheld-electronic dictionaries. Proceedings of Classic, 1018- 1024. Retrieved March 5, 2010, from http://www.paccall.org/2004/2004proceedings_papers/koyama.pdf

24. Krashen, S. (1985). The Input Hypothesis: Issues and implication. London and New York: Longman.

25. Krashen, S. (1989). We acquire vocabulary and spelling by reading: Additional evidence for the input hypothesis. The Modern Language Journal, 73, 440- 464.

26. Kroll, J. F., \& Stewart, E. (1994). Category interference in translation and picture naming: Evidence for asymmetric connections between bilingual memory representations. Journal of Memory and Language, 33(2), 149-74.

27. Kroll, J. F., \& Sunderman, G. (2003). Cognitive processes in second language learners and bilinguals: The development of lexical and conceptual representations. In C. J. Doughty, \& M. H. Long (Eds.) The Handbook of SLA (pp. 104-29). Malden, MA: Blackwell Publishing.

28. Laufer, B. (2001). Reading, word-focused activities and incidental vocabulary acquisition in a second language. Prospect, 16, 44-54.

29. Laufer, B. \& Hulstijn, J. (2001). Incidental vocabulary acquisition in a second language. The construct of task-induced involvement. Applied Linguistics, 22, 1-26.

30. McCarthy, M. (1990). Vocabulary. Oxford: Oxford University Press.

31. Meara, P. (1997). Towards a new approach to modelling vocabulary acquisition. In N. Schmitt \& M. McCarthy (Eds.), Vocabulary: Description, Acquisition and Pedagogy, (pp. 109-121). Cambridge:

Cambridge University Press. 
32. Min, H. T. (2008). EFL vocabulary acquisition and retention: Reading plus vocabulary enhancement activities and narrow reading. Language Learning, 58(1), 73-115.

33. Miyasako, N. (2002). Does text-glossing have any effects on incidental vocabulary learning through reading for Japanese senior high school students? Language Education \& Technology, 39, 1-20.

34. Nagy, W. E., \& Herman, P. A. (1987). Breadth and depth of vocabulary knowledge: Implications for acquisition and instruction. In M. G. McKeown \& M. Curtis (Eds.), The nature of vocabulary acquisition (pp. 19-35). Hillsdale, NJ: Erlbaum.

35. Nation, I. S. P. (2001). Learning vocabulary in another language. Cambridge, England: Cambridge University Press, pp. 236-240.

36. Newton, J. (1995). Task-based interaction and incidental vocabulary learning: a case study. Second Language Research, 11, 159-77.

37. Oxford, R., \& Scarcella, R. (1994). Second language vocabulary learning among adults: State of the art in vocabulary instruction. System, 22, 231-243.

38. Paribakht, T., \& Wesche, M. (1997). Vocabulary enhancement activities and reading for meaning in second language acquisition. In. J. Coady, \& T. Huckin (Eds.), Second Language Vocabulary Acquisition (pp. 174-200). Cambridge: Cambridge University Press.

39. Peters, E. (2007). Manipulating L2 learners' online dictionary use and its effect on L2 word retention. Language Learning \& Technology, 11, 36-58.

40. Prichard, C. (2008). Evaluating L2 readers' vocabulary strategies and dictionary use. Reading in a Foreign Language, 20(2), 219-231.

41. Pulido, D. (2007). The relationship between text comprehension and second language incidental vocabulary acquisition: A matter if topic familiarity? Language Learning, 57, 155-199.

42. Rieder, A. (2003) Implicit and explicit learning in incidental vocabulary acquisition. Vienna Working Papers, 12, 24-39.

43. Robinson, P. (2003). Attention and memory. In C. Doughty \& M. H. Long (Eds.), Handbook of second language acquisition (pp. 631-678). Oxford: Blackwell.

44. Roby, W. B. (1999). What's in a gloss? Language Learning \& Technology, 2, 94-101.

45. Schmidt, R. (1995). Consciousness and foreign language learning: A tutorial on the role of attention and awareness in learning. Attention and Awareness in Foreign Language Learning (pp. 1-65). R. Schmidt. Hawai'i, University of Hawai'i, Second Language Teaching and Curriculum Center.

46. Schmidt, R. (2001). Attention. In P. Robinson (Ed.), Cognition and second language instruction (pp. 3-32). Cambridge: Cambridge University Press.

47. Schmitt, N. (2000). Vocabulary in Language Teaching. Cambridge: Cambridge University Press.

48. Schmitt, N. (2008). "Review article: Instructed second language vocabulary learning." Language Teaching Research, 12(3), 329-363.

49. Skehan, P. (1998) A Cognitive Approach to Language Learning. Oxford: Oxford University Press.

50. Swain, M. (1985). Communicative competence: Some roles of comprehensible input and comprehensible output in its development. In Gass, S. and Madden, C. (Eds.), Input in Second Language Acquisition (pp. 235-256). New York: Newbury House.

51. Waring, R. (2002). Why should we build up a Start-up vocabulary quickly? Retrieved March 5, 2011, from: http://www1.harenet.ne.jp/ waring/vocab/principles/early.htm

52. Wesche, M., \& Paribakht, T. S. (2000). Reading-Based Exercises in Second Language Vocabulary Learning: An Introspective Study. The Modern Language Journal, 84(2), 197-198.

53. Yoshii, M. (2006) L1 and L2 glosses: their effects on incidental vocabulary learning. Language Learning \& Technology, 10(3), 85-101.

54. Zhang, L. J. (2001). Awareness in reading: EFL students' metacognitive knowledge of reading strategies in an acquisition-poor environment. Language Awareness, 10, 268-88. 